\title{
Systemic and Cellular Reflections on Ageing and the Circadian Oscillator - A Mini-Review
}

\author{
Steven A. Brown ${ }^{a}$ Lucia Pagani ${ }^{b}$ Christian Cajochen ${ }^{c}$ Anne Eckert ${ }^{b}$ \\ ${ }^{a}$ Department of Pharmacology and Toxicology, University of Zurich, Zurich, and ${ }^{\mathrm{b}}$ Neurobiology Laboratory \\ for Brain Aging and Mental Health, and ' Centre for Chronobiology, Psychiatric University Clinics Basel, \\ Basel, Switzerland
}

\section{Key Words}

Circadian rhythm $\cdot$ Biological clock $\cdot$ Physiology

\begin{abstract}
From circulation to digestion to excretion, a circadian clock synchronizes most aspects of mammalian physiology with the solar day. During normal ageing, this daily coordination gradually erodes, and during pathological ageing such erosion is exacerbated. Recent experiments suggest that therapies aimed at sustaining circadian function increase quality of life in elderly patients. Hence, a better understanding of the interactions between the circadian clock and ageing - at both cellular and systemic levels - could lead to direct benefits for aged individuals.

Copyright $\odot 2010$ S. Karger AG, Basel
\end{abstract}

From archaebacteria to humans, a biological clock has governed most aspects of cellular and systemic function. In mammals, $10 \%$ of all genes are expressed rhythmically in daily fashion, coordinated with the solar day. Hence, it is not surprising that nearly all aspects of physiology and behavior are governed by this 'circadian' oscil- lator [1]. Within the circulatory system, heartbeat and blood pressure vary in diurnal fashion, and rhythmic expression of genes involved in fibrinolysis are believed to contribute to the prevalence of infarctus at morning hours [2]. Similarly, circadian detoxication of many xenobiotic substances is controlled by cyclic expression of cytochrome enzymes [3], and daily variations in mood and alertness might be explained in part by circadian expression of ion channels, neuronal receptors and hormones $[4,5]$.

As the body ages, this coordination deteriorates in universal fashion: the circadian organization of the sleepwake cycle is disrupted, and with it most other physiological manifestations of the circadian clock become less pronounced [6]. In situations of pathological ageing such as dementia as well as Huntington's and Parkinson's diseases, initial disease stages are marked by abnormal daily behavior, and later stages are correlated with almost total loss of circadian function $[7,8]$. An understanding of this deterioration could therefore be of great assistance in increasing the quality of life for elderly individuals. Incorrectly, many of these disturbances are ascribed simply to 'sleep difficulties': in Western countries, 1 in 5 elderly people reports taking a sleep medication regularly [9].

\section{KARGER}

Fax +4161306 1234

E-Mail karger@karger.ch

www.karger.com
(C) 2010 S. Karger AG, Basel

0304-324X/11/0575-0427\$38.00/0

Accessible online at:

www.karger.com/ger
Prof. Steven A. Brown

Department of Pharmacology and Toxicology, University of Zurich

Winterthurerstrasse 190

$\mathrm{CH}-8057$ Zurich (Switzerland)

Tel. +41 44635 5999, Fax +41 44635 5707, E-Mail steven.brown@ @harma.uzh.ch 
While these may provide a momentary alleviation of fatigue, underlying causes remain unaddressed, leading to a chronic dependence upon these substances.

\section{How Is Circadian Function Regulated?}

In all mammals including humans, the suprachiasmatic nucleus (SCN) of the brain hypothalamus acts as a central clock tissue, coordinating all aspects of overt daily physiology and behavior. However, its mechanism is cell autonomous: each individual neuron of the SCN possesses a separate functional oscillator at the cellular level [10]. The individual clocks in each neuron are kept in phase with one another by intercellular communication involving neuropeptidergic signaling and electrical synapses $[11,12]$. The nucleus as a whole then synchronizes circadian timing throughout the body, probably through a combination of diffusible factors and direct connections to other brain regions $[13,14]$. In fact, 'slave' oscillators of similar or identical molecular mechanism to those in the SCN are present throughout the body as well. Dissociated cells of peripheral tissues such as fibroblasts appear to be able to keep time as accurately as SCN neurons in culture [15]. Regulation of daily physiology and behavior is probably a product of systemic regulation of some processes directly by the SCN, and indirect regulation of others directly by cellular clocks in other tissues [16]. Such a system has the potential benefit of temporary uncoupling between SCN and peripheral clocks. For example, if rodents are fed consistently at an abnormal time, their peripheral clocks in the liver, kidney and other organs will change their circadian phase to reflect the new feeding time, but the SCN will continue to remain in synchrony with the solar day $[17,18]$.

At a cellular level, the mammalian circadian oscillator is composed of interlocking feedback loops of transcription and translation. A variety of dedicated genes are used for this purpose: the products of the Clock and Bmal1 loci activate transcription of a set of afternoonactive genes including the period and cryptochrome family via cis-acting E-box elements present in the promoter regions of these genes. PER and CRY proteins then oligomerize to form a repressive complex that counteracts CLOCK:BMAL1 activation and shuts off their own transcription so that the cycle can begin anew. Added robustness and control of this mechanism is provided by secondary feedback loops of transcription factors (for example the nuclear hormone receptors REV-ERB $\alpha$ and ROR- $\alpha$ ), by phosphorylation (for example casein kinases
1 and 2, GSK3, and likely multiple others), and by chromatin-modifying factors, RNA-binding proteins and cellular metabolic components like cAMP [19]. Elegantly, because this clockwork is present in most cells of the body, it is also one way that is used to control circadian output directly: the same elements critical for transcription of clock genes are also present in the promoters of many clock-controlled genes, where they drive circadian transcription using proteins from the clock itself [20].

\section{Entrainment}

To better understand how circadian synchrony might be impaired in older individuals, it is important to understand how it is entrained in the first place. In the absence of external signals that entrain the clock, the mammalian circadian clock will 'free run' at its endogenous genetically programmed circadian period. This period is approximately but not exactly $24 \mathrm{~h}$. In fact, that is why this biological clock is called 'circadian' - from the Latin 'circa diem' or 'around a day'. Thus, without external timing cues, an organism will eventually drift out of synchrony with the actual solar day. Preventing this are entrainment signals that come from the environment. In mammals, entrainment of the central clock in the SCN is a predominantly ocular process. Environmental light is transduced from the retina via both conventional rod and cone photoreceptors containing the photopigment rhodopsin, and via a special class of retinal ganglion cells containing the pigment melanopsin [21]. These cells project directly to the SCN. Without these retinal cells - for example, in some totally blind or enucleated individuals - the circadian clock free runs, leaving affected people with chronic jetlag-like symptoms [22].

Light transduction through the lens of the eye is reduced in elderly individuals, particularly in the short wavelength range $(<480 \mathrm{~nm})$ [23]. Elderly mice show much smaller light-induced clock changes ('phase shifting') than young ones [24], and elderly individuals attenuated phase advances by ocular bright light exposure in the morning [25]. In addition, there is a loss of retinal ganglion cells that transmit light signals to the circadian timing system in older animals of multiple species [26]. Hence, it has been speculated that one cause of circadian disturbances in elderly subjects is an inability to entrain properly to the environment. Such problems might be particularly acute in a clinical setting, where lighting can be irregular or even constant (for example, the hospital intensive care unit), or during nursing care when patients 
receive little natural light. Recent human studies provide evidence for this hypothesis and show that the human circadian system is less sensitive to light in the elderly [27, 28]. Moreover, practically speaking, bright diurnal lighting in nursing homes has improved behavioral circadian rhythms in residents and improved sleep quality [29] as well as cognitive performance and mood [30]. Similar results are seen for demented individuals [31]. By contrast, constant bright lighting might also have deleterious effects: at least in animal models, constant light can desynchronize SCN neurons [32] and, as discussed at the end of this review, impaired clockwork is linked to a variety of pathologies including cancer and immune dysfunction.

The degree to which brain- and eye-related entrainment changes in the elderly are mirrored or relayed in peripheral tissues remains controversial: age-dependent changes in clock gene amplitude (such as Per2 and Per3 genes) can be observed in blood leukocytes and oral keratinocyes, but no age-dependent differences are seen in phase shifting in these cells $[33,34]$. This question of entrainment of peripheral organs is discussed more fully next. It is clear, though, that relatively inexpensive and easy benefits can be obtained by ensuring that elderly patients under clinical care receive adequate light in circadian fashion.

\section{Systemic Considerations}

As mentioned already, the SCN 'master clock' is entrained by light, and it in turn entrains slave oscillators in most cells of the body via a myriad of redundant cues. One important class is nervous signals. The neurons of the SCN demonstrate spontaneous firing patterns in daily fashion [10, 35], and project to many other brain nuclei [13], where they are presumed to be important for sleepwake cycles and cognitive function. Paradoxically, however, the first line of communication from the SCN to centers controlling locomotor activity is probably hormonal: animal experiments show that implantation of SCN neurons encapsulated in porous plastic are still capable of rescuing rhythmicity in SCN-lesioned animals [14]. In peripheral tissues, the sympathetic nervous system also plays an important role, and has been shown to communicate timing signals directly to the adrenal gland and other tissues [36]. This signaling methodology is likely one of the methods by which daily rhythms of corticosterone synthesis are generated [37].

Systemic and Cellular Reflections on Ageing and the Circadian Oscillator
A second class of signals is indirect products of the regulation of other brain centers by the SCN. Body temperature is one important class: even though daily body temperature varies by only $1-4^{\circ} \mathrm{C}$ in mammals, these faint daily fluctuations - probably controlled by SCN innervation of the preoptic anterior hypothalamus and by daily activity patterns - are sufficient to entrain peripheral tissues [38]. Similarly, daily patterns of feeding are likely cues for the entrainment of peripheral clocks in tissues throughout the body $[17,18]$, as well as a separate 'food-entrainable' brain oscillator that can control locomotor activity in the absence of the known circadian clock $[39,40]$. In animals, alterations of either of these classes of signals effectively 'decouple' the central clock from oscillators in other tissues: either reversal of daily body temperature rhythms [38] or of daily feeding rhythms $[17,18]$ can inverse the timing of local clocks in peripheral organs. The exact mechanism of this regulation remains unknown, but recent research proposes direct molecular coupling between metabolic cycles and the circadian oscillator via redox-regulated 'sirtuin' proteins [41, 42], and such a metabolic link could be a plausible signal, at least for food-based entrainment. In reverse, brain-regulated corticosterone rhythms probably serve as a stabilizing influence: in animals lacking the glucocorticoid receptor in the liver, liver clocks are much more rapidly shifted by alterations in daily feeding patterns [43].

From these experiments, one can speculate that another way in which circadian oscillations might be dampened in elderly individuals might be through alterations of systemic entrainment pathways. For example, in one study, aged rats showed normal entrainment of the SCN by light, but severely disrupted liver clock entrainment [44]. We hypothesize that well-characterized alterations in the hypothalamic-adrenal-pituitary axis in elderly individuals might play a major role. For example, circadian oscillation of cortisol is dampened, peak levels are reduced and evening levels are increased in older people [45]. This condition would act synergistically: not only would the direct circadian effects of cortisol upon digestion and detoxification be lost, but also any effects of irregular feeding and body temperature would have even greater effects upon the circadian oscillator because of impairment of parallel cortisol-based entrainment mechanisms. Multiple studies have shown that imposed regular routines of mealtime and exercise improve circadian consolidation of sleep-wake cycles in elderly individuals $[29,46]$. Physiologically speaking, meal and light routines might help substitute for the loss of internal circadian 
signals, and themselves act as timing cues. Under normal conditions in young, healthy individuals, factors such as meal timing are overpowered by systemic circadian cues, and therefore might play a less important role. A similar situation exists in blind individuals: in the absence of the strong influence of ocular light, many subjects can be entrained to the 24-hour day by weak nonphotic timing cues that do not play a significant role for sighted individuals [47].

\section{Cellular Considerations}

As already described, virtually all cells in mammals have an independent circadian clock capable of sustained oscillations in isolation. Because each cellular oscillator is slightly different, though, circadian oscillations in dispersed cultures or tissue slices of peripheral cells rapidly dampen. The function of the redundant signaling described above is to synchronize all cellular clocks, thereby sustaining robust rhythms of gene expression and physiology at the tissue level. Recent studies suggest that there is a second function, though: to drive a subset of cellular circadian gene expression directly. Thus, genetically modified mice lacking a functional circadian clock in a particular organ lose circadian expression of a subset of genes (those coupled to the cellular oscillator) but still show circadian expression of others (those coupled to systemic mechanisms) $[48,49]$. Similarly, tissue-specific rescue of a clock gene results in rescue of only a subset of physiological aspects of the underlying mutant strain [50].

The cellular heterogeneity of clock properties probably serves a definite function. Although the day length on our planet is fixed to $24 \mathrm{~h}$, the period of light during this time can vary dramatically in lateral clines. To cope with these differences, the circadian clock is able to track both light onset (dawn) and light offset (dusk). Because of cellular differences in the SCN, some of its cellular clocks are phased earlier, and thereby track dawn, and others are phased later to track dusk - a hypothesis formed long before the existence of cellular clocks was discovered [51], and recently confirmed in rodent SCN neural activity studies [52] as well as luciferase imaging experiments [53]. To keep SCN cells locally synchronized, neurochemical coupling mechanisms are used $[12,54]$, and probably gap junctions as well [55]. Elimination of these components in mice results in dramatically dampened circadian oscillations.
These cellular mechanisms comprise yet another way in which circadian rhythms could be altered in older individuals. It is possible that cellular clocks are themselves altered in aged cells, either intrinsically or due to increased release of inflammatory cytokines which are known to affect circadian gene expression $[56,57]$. Alternatively, changes in synaptic patterns and neurochemical coupling within the SCN could also result in alterations in cellular clock function [58,59]. Lending credence to this hypothesis, SCN electrical firing shows reduced circadian amplitude in older rats $[60,61]$ and reduced sensitivity to the hormone melatonin [62]. Transplantation of a fetal SCN into aged hamsters improved behavioral rhythmicity $[63,64]$.

\section{Circadian Alterations in the Elderly: Working Backwards}

A great deal of research has been done to characterize the specific physiological changes that occur as humans age, and some of these have already been mentioned above. The nature of these changes could permit us to understand better which of the mechanisms presented above might be responsible for the decline in circadian function in elderly individuals.

Even based upon simple questionnaires, it is clear that from adolescence onward, human circadian clocks move earlier as individuals age. Between the ages of 20 and 80 years, the timing of sleep shifts an average of $2 \mathrm{~h}$ [65]. At the same time, sleep consolidation - that is the ability to sleep in long, unbroken nighttime bouts - is decreased. In addition, the total amount of slow-wave 'deep' sleep decreases and rapid-eye-movement 'dream' sleep is more evenly distributed [66]. In short, there is a marked decrease in the 'circadian amplitude' of sleep. Sleep patterns are believed to be the sum of two independent processes: a circadian one that programs human beings to sleep preferentially at night and a homeostatic one that increases sleep pressure with increasing time awake [67]. In principle, the fragmentation of sleep could be caused either by a reduction in the strength of the circadian component or by a change in the homeostatic component, and this question is actively debated at present.

The reduction in circadian amplitude is not limited to sleep: it is universal and results in a variety of endocrine consequences. Appetite is reduced during meals and intermeal eating increases, and activity is increased during nighttime hours, especially during pathological ageing (dementia, Huntington's and Parkinson's disease). Mean- 


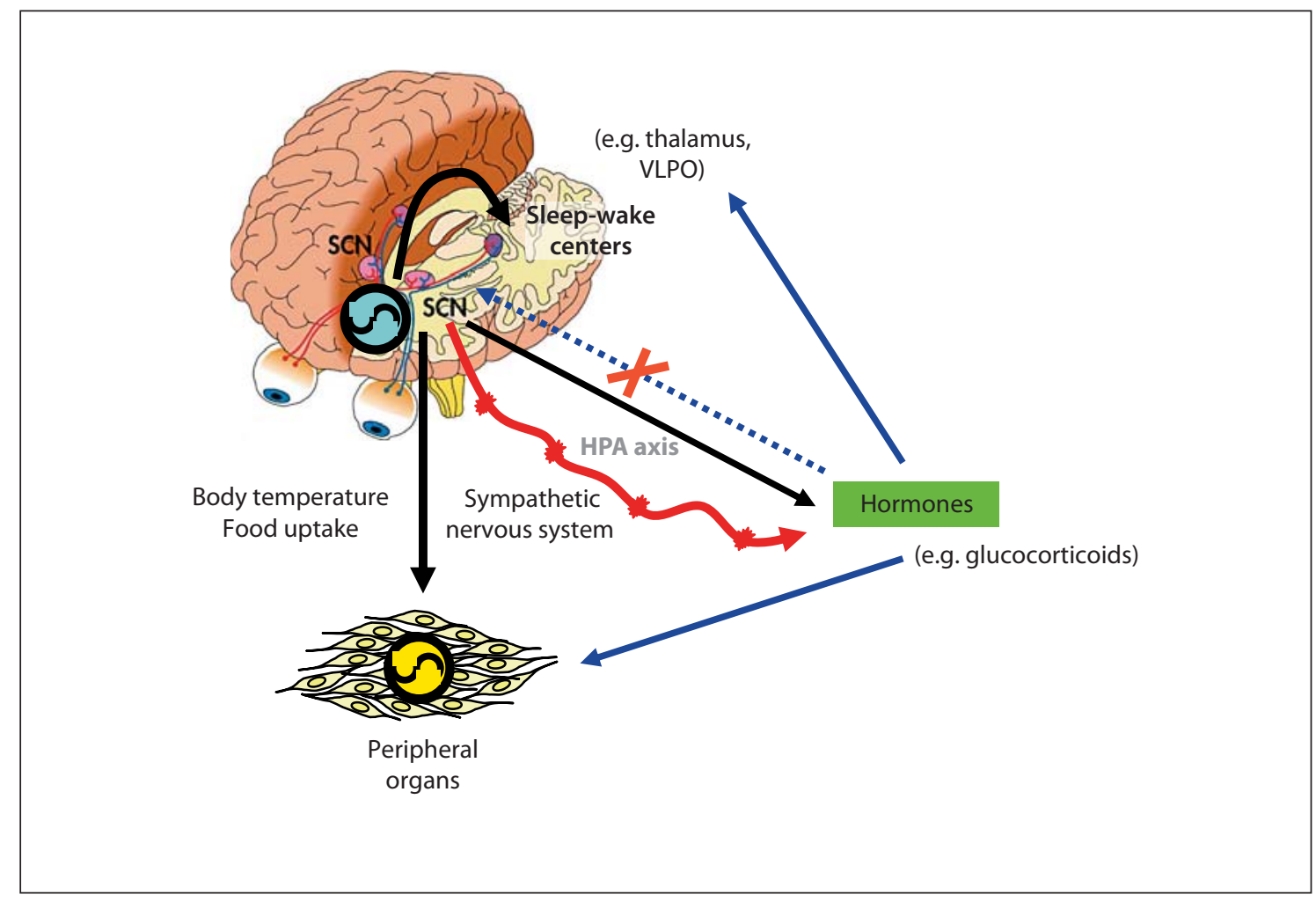

Fig. 1. Interaction between master and peripheral clocks. In mammals, the master clock in the SCN communicates timing information to other tissues in the brain and body via a redundant combination of signals: nervous innervation of other brain regions, secreted hormones, and indirect cues like body temperature and food intake (shown as black arrows leading out from the SCN), as well as by sympathetic innervation of peripheral organs (red arrow). Hormonal signals that influence circadian phase can in turn affect both peripheral organs and sleep-wake centers (blue arrows). We suggest that some of these hormones (such as glucocor-

while, the circadian amplitude and magnitude of many hormones are reduced, especially melatonin, prolactin, those of the hypothalamic-adrenal-pituitary axis as well as glucose [68]. Although some studies are contradictory on this point, body temperature may be both lower and oscillate with lower circadian amplitude [69]. Endothelial nitric oxide oscillations are also reduced and may be responsible for the damping of circadian cardiac function [70]. In short, it is easy to imagine how circadian physiology might be attenuated.

A thornier problem is what might shift phase. One obvious hypothesis to explain earlier phase would be a shortening of the period of the circadian oscillator. Intrinsic period shortening has been observed in aged rodents and nonhuman primates by some groups [71, 72]. ticoids) cannot signal to the SCN (dashed blue arrow), though they can still affect sleep-wake centers. In older individuals, the circadian amplitude of signals from the SCN is decreased, resulting in sleep fragmentation and reduced amplitudes of circadian behavior and physiology. We propose that at the same time, changes in hormonal balance - perhaps in the hypothalamic-pituitary-adrenal (HPA) axis - would additionally alter the circadian phase of behavior. Because these hormones do not 'feed back' to the SCN, they would not change circadian period length under free-running conditions.
In humans, laboratory studies make this hypothesis unlikely: cross-sectional studies of younger and older adults under 'forced desynchrony' - artificial lighting conditions that measure the intrinsic period of the circadian oscillator unaffected by external environment - show no differences in average period length [73]. Interestingly, the same studies also show that the timing ('phase angle') of sleep relative to the circadian clock (measured via the pattern of secretion of the circadian hormone melatonin) is earlier and sleep is less consolidated [74, 75]. It is this lack of sleep consolidation that has led other groups to speculate that sleep fragmentation is itself responsible for the circadian phase shift [76].

According to this idea, age-related changes in sleep structure and sleep consolidation reflect a reduction in 
the circadian force that opposes homeostatic sleep pressure [77]. This influence is particularly significant in the late evening, when the circadian drive for wakefulness is highest (that is, the wake maintenance zone), and in the early morning hours, when the circadian drive for sleep is at its maximum, thus leading to more sleep episodes in the evening and earlier morning wakening in elderly individuals. As a consequence of this altered sleep-wake pattern, the elderly may expose themselves to more morning than evening light, which may result in an earlier circadian phase.

This model works well in normal conditions, but it does not fully explain similar results studying sleep latency under forced desynchrony conditions that look at the free-running circadian oscillator [73]. We suggest that this paradox might be explained by hormonal changes, and that the same hormonal differences might also explain the reduced circadian drive discussed previously. Since many hormones phase shift peripheral circadian clocks, alterations in their overall levels would be predicted to alter period in free-running conditions and phase in an entrained environment. However, if these hormones do not act upon the SCN - due to the bloodbrain barrier or a lack of the appropriate receptors -, the result would be a shift in the phase of circadian physiology (controlled most directly by peripheral organs and brain regions) without a change in the free-running period of circadian behavior (controlled by the SCN) (fig. 1).

\section{Pathological Effects of Reduced Circadian Function in Older Individuals}

The obvious effect of decreased circadian amplitude is a decreased quality of life, probably driven by worse sleep and a feeling of less energy during active periods. An increasing number of mouse studies suggest that decreased circadian function might also have a direct effect upon life span. These studies fall into three classes. First, there are mouse studies showing that deletions of some clock genes (for example, Bmall and Per2) lead to decreased life span and increased cancer as well as other age-related pathologies $[78,79]$. Though interesting, metabolic defects linked to deletions of these genes make it unclear if their effects are gene or clock specific. Secondly, there are studies suggesting that circadian desynchrony per se - via chronic jet lag paradigms, for example - leads to decreased life span [80] and increased cancer rate and tumor growth [81]. Finally, an increasing number of mechanistic studies tie the circadian clock intimately to questions of metabolism. They show for example that the circadian clock times cell division in adult animals [82], and that it regulates and is regulated by proteins sensitive to cellular reduction and oxidation like sirtuins, which have themselves garnered a great deal of interest as antiageing proteins [83]. Thus, the circadian clock may be fundamentally tied to the balance of factors that prevent cellular damage, and reduced circadian amplitude may therefore accelerate this process.

Although not discussed herein, other pathological effects may also arise separately through the changes in sleep that come about during ageing. For example, sleep deprivation results in immune system dysfunction and chronic inflammation. Since these two effects are commonly observed in aged individuals who suffer from disturbed sleep, it is easy to hypothesize a causative link [84]. Other studies, however, suggest that, according to cognitive parameters, healthy subjects actually tolerate sleep deprivation better than younger ones, belying the idea that they are sleep-deprived because of their altered sleep structure [85]. Further research is clearly needed upon this interesting question.

\section{Perspective on Experiments and Treatments}

Because the synchronization of peripheral circadian oscillators can be driven by indirect cues such as mealtime and body temperature, some of the best current circadian therapies for elderly individuals may also be the simplest: timed regular activities and mealtimes as well as bright daytime light. Multiple reports from clinical settings already suggest that these measures can help. In the longer term, the susceptibility of peripheral clocks to multiple hormones may make hormonal therapies another viable option. Exactly which hormones might be effective - and which, if any, might be responsible for these changes in the first place - are experimentally testable hypotheses, particularly given easy access to peripheral clocks in some human tissues. Thus, it is likely that future experiments cannot only help illuminate the causes of circadian dysfunction in the elderly, but also help alleviate it in a safe manner. 


\section{References}

1 Gachon F, Nagoshi E, Brown SA, Ripperger J, Schibler U: The mammalian circadian timing system: from gene expression to physiology. Chromosoma 2004;113:103-112.

$>2$ Westgate EJ, Cheng Y, Reilly DF, Price TS, Walisser JA, Bradfield CA, FitzGerald GA: Genetic components of the circadian clock regulate thrombogenesis in vivo. Circulation 2008;117:2087-2095.

$>3$ Froy O: Cytochrome P450 and the biological clock in mammals. Curr Drug Metab 2009; 10:104-115.

4 McClung CA: Circadian genes, rhythms and the biology of mood disorders. Pharmacol Ther 2007;114:222-232.

$\checkmark 5$ Ko GY, Shi L, Ko ML: Circadian regulation of ion channels and their functions. J Neurochem 2009;110:1150-1169.

6 Gibson EM, Williams WP 3rd, Kriegsfeld LJ: Aging in the circadian system: considerations for health, disease prevention and longevity. Exp Gerontol 2009;44:51-56.

$>7$ Morton AJ, Wood NI, Hastings MH, Hurelbrink C, Barker RA, Maywood ES: Disintegration of the sleep-wake cycle and circadian timing in Huntington's disease. J Neurosci 2005;25:157-163.

$>8$ Wu YH, Swaab DF: Disturbance and strategies for reactivation of the circadian rhythm system in aging and Alzheimer's disease. Sleep Med 2007;8:623-636.

$>9$ Englert S, Linden M: Differences in self-reported sleep complaints in elderly persons living in the community who do or do not take sleep medication. J Clin Psychiatry 1998;59:137-144; quiz 145

-10 Welsh DK, Logothetis DE, Meister M, Reppert SM: Individual neurons dissociated from rat suprachiasmatic nucleus express independently phased circadian firing rhythms. Neuron 1995;14:697-706.

$>11$ Colwell CS: Rhythmic coupling among cells in the suprachiasmatic nucleus. J Neurobiol 2000;43:379-388.

-12 Maywood ES, Reddy AB, Wong GK, O’Neill JS, O’Brien JA, McMahon DG, Harmar AJ, Okamura H, Hastings MH: Synchronization and maintenance of timekeeping in suprachiasmatic circadian clock cells by neuropeptidergic signaling. Curr Biol 2006;16: 599-605.

13 Leak RK, Moore RY: Topographic organization of suprachiasmatic nucleus projection neurons. J Comp Neurol 2001;433:312-334.

-14 Silver R, LeSauter J, Tresco PA, Lehman MN: A diffusible coupling signal from the transplanted suprachiasmatic nucleus controlling circadian locomotor rhythms. Nature 1996; 382:810-813.

$\checkmark 15$ Welsh DK, Yoo SH, Liu AC, Takahashi JS, Kay SA: Bioluminescence imaging of individual fibroblasts reveals persistent, independently phased circadian rhythms of clock gene expression. Curr Biol 2004;14:22892295.
16 Kowalska E, Brown SA: Peripheral clocks: keeping up with the master clock. Cold Spring Harb Symp Quant Biol 2007;72:301305.

17 Damiola F, Le Minh N, Preitner N, Kornmann B, Fleury-Olela F, Schibler U: Restricted feeding uncouples circadian oscillators in peripheral tissues from the central pacemaker in the suprachiasmatic nucleus. Genes Dev 2000;14:2950-2961.

18 Stokkan KA, Yamazaki S, Tei H, Sakaki Y, Menaker M: Entrainment of the circadian clock in the liver by feeding. Science 2001; 291:490-493.

19 Albrecht U (ed): The Circadian Clock. New York, Springer Science and Business Media, 2010.

20 Ripperger JA, Schibler U: Rhythmic CLOCKBMAL1 binding to multiple E-box motifs drives circadian Dbp transcription and chromatin transitions. Nat Genet 2006;38: 369-374.

21 Hattar S, Lucas RJ, Mrosovsky N, Thompson S, Douglas RH, Hankins MW, Lem J, Biel M, Hofmann F, Foster RG, Yau KW: Melanopsin and rod-cone photoreceptive systems account for all major accessory visual functions in mice. Nature 2003;424:76-81.

22 Lockley SW, Arendt J, Skene DJ: Visual impairment and circadian rhythm disorders. Dialogues Clin Neurosci 2007;9:301-314.

23 Said FS, Weale RA: The variation with age of the spectral transmissivity of the living human crystalline lens. Gerontologia 1959;3: 213-231.

24 Benloucif S, Masana MI, Dubocovich ML: Responsiveness to melatonin and its receptor expression in the aging circadian clock of mice. Am J Physiol 1997;273:R1855-R1860.

25 Klerman EB, Duffy JF, Dijk DJ, Czeisler CA: Circadian phase resetting in older people by ocular bright light exposure. J Investig Med 2001;49:30-40.

26 Neufeld AH, Gachie EN: The inherent, agedependent loss of retinal ganglion cells is related to the lifespan of the species. Neurobiol Aging 2003;24:167-172.

27 Duffy JF, Zeitzer JM, Czeisler CA: Decreased sensitivity to phase-delaying effects of moderate intensity light in older subjects. Neurobiol Aging 2007;28:799-807.

28 Sletten TL, Revell VL, Middleton B, Lederle KA, Skene DJ: Age-related changes in acute and phase-advancing responses to monochromatic light. J Biol Rhythms 2009;24:7384.

29 Alessi CA, Martin JL, Webber AP, Cynthia Kim E, Harker JO, Josephson KR: Randomized, controlled trial of a nonpharmacological intervention to improve abnormal sleep/ wake patterns in nursing home residents. J Am Geriatr Soc 2005;53:803-810.
30 Riemersma-van der Lek RF, Swaab DF, Twisk J, Hol EM, Hoogendijk WJ, Van Someren EJ: Effect of bright light and melatonin on cognitive and noncognitive function in elderly residents of group care facilities: a randomized controlled trial. JAMA 2008;299:26422655.

31 Mishima K, Okawa M, Hishikawa Y, Hozumi S, Hori H, Takahashi K: Morning bright light therapy for sleep and behavior disorders in elderly patients with dementia. Acta Psychiatr Scand 1994;89:1-7.

-32 Ohta H, Yamazaki S, McMahon DG: Constant light desynchronizes mammalian clock neurons. Nat Neurosci 2005;8:267269.

33 Ackermann K, Sletten TL, Revell VL, Archer SN, Skene DJ: Blue-light phase shifts PER3 gene expression in human leukocytes. Chronobiol Int 2009;26:769-779.

-34 Jud C, Chappuis S, Revell VL, Sletten TL, Saaltink DJ, Cajochen C, Skene DJ, Albrecht $\mathrm{U}$ : Age-dependent alterations in human PER2 levels after early morning blue light exposure. Chronobiol Int 2009;26:1462-1469.

35 Inouye ST, Kawamura H: Persistence of circadian rhythmicity in a mammalian hypothalamic 'island' containing the suprachiasmatic nucleus. Proc Natl Acad Sci USA 1979; 76:5962-5966

36 Okamura H: Suprachiasmatic nucleus clock time in the mammalian circadian system. Cold Spring Harb Symp Quant Biol 2007;72: 551-556.

-37 Engeland WC, Arnhold MM: Neural circuitry in the regulation of adrenal corticosterone rhythmicity. Endocrine 2005;28:325-332.

-38 Brown SA, Zumbrunn G, Fleury-Olela F, Preitner N, Schibler U: Rhythms of mammalian body temperature can sustain peripheral circadian clocks. Curr Biol 2002;12: 1574-1583.

39 Storch KF, Weitz CJ: Daily rhythms of foodanticipatory behavioral activity do not require the known circadian clock. Proc Natl Acad Sci USA 2009;106:6808-6813.

-40 Fuller PM, Lu J, Saper CB: Differential rescue of light- and food-entrainable circadian rhythms. Science 2008;320:1074-1077.

-41 Asher G, Gatfield D, Stratmann M, Reinke H, Dibner C, Kreppel F, Mostoslavsky R, Alt FW, Schibler U: SIRT1 regulates circadian clock gene expression through PER2 deacetylation. Cell 2008;134:317-328.

-42 Nakahata Y, Sahar S, Astarita G, Kaluzova M, Sassone-Corsi P: Circadian control of the NAD+ salvage pathway by CLOCK-SIRT1. Science 2009;324:654-657.

43 Le Minh N, Damiola F, Tronche F, Schutz G, Schibler U: Glucocorticoid hormones inhibit food-induced phase-shifting of peripheral circadian oscillators. Embo J 2001;20:71287136. 
-44 Davidson AJ, Yamazaki S, Arble DM, Menaker M, Block GD: Resetting of central and peripheral circadian oscillators in aged rats. Neurobiol Aging 2008;29:471-477.

-45 Ferrari E, Cravello L, Muzzoni B, Casarotti D, Paltro M, Solerte SB, Fioravanti M, Cuzzoni G, Pontiggia B, Magri F: Age-related changes of the hypothalamic-pituitary-adrenal axis: pathophysiological correlates. Eur J Endocrinol 2001;144:319-329.

-46 Martin JL, Marler MR, Harker JO, Josephson KR, Alessi CA: A multicomponent nonpharmacological intervention improves activity rhythms among nursing home residents with disrupted sleep/wake patterns. J Gerontol A Biol Sci Med Sci 2007;62:67-72.

-47 Mistlberger RE, Skene DJ: Nonphotic entrainment in humans? J Biol Rhythms 2005; 20:339-352.

-48 Kornmann B, Schaad O, Bujard H, Takahashi JS, Schibler U: System-driven and oscillator-dependent circadian transcription in mice with a conditionally active liver clock. PLoS Biol 2007;5:e34.

-49 Lamia KA, Storch KF, Weitz CJ: Physiological significance of a peripheral tissue circadian clock. Proc Natl Acad Sci USA 2008; 105:15172-15177.

- 50 McDearmon EL, Patel KN, Ko CH, Walisser JA, Schook AC, Chong JL, Wilsbacher LD, Song EJ, Hong HK, Bradfield CA, Takahashi JS: Dissecting the functions of the mammalian clock protein BMAL1 by tissue-specific rescue in mice. Science 2006;314:1304-1308.

-51 Pittendrigh CS, Daan S: A functional analysis of circadian pacemakers in nocturnal rodents. V. Pacemaker structure: a clock for all seasons. J Comp Physiol A 1976;106:333355.

-52 Jagota A, de la Iglesia HO, Schwartz WJ: Morning and evening circadian oscillations in the suprachiasmatic nucleus in vitro. Nat Neurosci 2000;3:372-376.

53 Inagaki N, Honma S, Ono D, Tanahashi Y, Honma K: Separate oscillating cell groups in mouse suprachiasmatic nucleus couple photoperiodically to the onset and end of daily activity. Proc Natl Acad Sci USA 2007;104 7664-7669.

- 54 Aton SJ, Colwell CS, Harmar AJ, Waschek J, Herzog ED: Vasoactive intestinal polypeptide mediates circadian rhythmicity and synchrony in mammalian clock neurons. Nat Neurosci 2005;8:476-483.

-55 Long MA, Jutras MJ, Connors BW, Burwell RD: Electrical synapses coordinate activity in the suprachiasmatic nucleus. Nat Neurosci 2005;8:61-66.

56 Cavadini G, Petrzilka S, Kohler P, Jud C, Tobler I, Birchler T, Fontana A: TNF- $\alpha$ suppresses the expression of clock genes by interfering with E-box-mediated transcription. Proc Natl Acad Sci USA 2007;104:1284312848.
Cayetanot F, Nygard M, Perret M, Kristensson K, Aujard F: Plasma levels of interferongamma correlate with age-related disturbances of circadian rhythms and survival in a non-human primate. Chronobiol Int 2009; 26:1587-1601.

58 Palomba M, Nygard M, Florenzano F, Bertini G, Kristensson K, Bentivoglio M: Decline of the presynaptic network, including GABAergic terminals, in the aging suprachiasmatic nucleus of the mouse. J Biol Rhythms 2008;23:220-231.

59 Kallo I, Kalamatianos T, Piggins HD, Coen CW: Ageing and the diurnal expression of mRNAs for vasoactive intestinal peptide and for the VPAC2 and PAC1 receptors in the suprachiasmatic nucleus of male rats. J Neuroendocrinol 2004;16:758-766.

-60 Satinoff E, Li H, Tcheng TK, Liu C, McArthur AJ, Medanic M, Gillette MU: Do the suprachiasmatic nuclei oscillate in old rats as they do in young ones? Am J Physiol 1993; 265:R1216-R1222.

61 Watanabe A, Shibata S, Watanabe S: Circadian rhythm of spontaneous neuronal activity in the suprachiasmatic nucleus of old hamster in vitro. Brain Res 1995;695:237239.

62 von Gall C, Weaver DR: Loss of responsiveness to melatonin in the aging mouse suprachiasmatic nucleus. Neurobiol Aging 2008; 29:464-470.

63 Viswanathan N, Davis FC: Suprachiasmatic nucleus grafts restore circadian function in aged hamsters. Brain Res 1995;686:10-16.

64 Hurd MW, Zimmer KA, Lehman MN, Ralph MR: Circadian locomotor rhythms in aged hamsters following suprachiasmatic transplant. Am J Physiol 1995;269:R958-R968.

65 Roenneberg T, Kuehnle T, Juda M, Kantermann T, Allebrandt K, Gordijn M, Merrow M: Epidemiology of the human circadian clock. Sleep Med Rev 2007;11:429-438.

66 Espiritu JR: Aging-related sleep changes. Clin Geriatr Med 2008;24:1-14, v.

67 Borbely AA: A two process model of sleep regulation. Hum Neurobiol 1982;1:195-204.

-68 Van Cauter E, Plat L, Leproult R, Copinschi G: Alterations of circadian rhythmicity and sleep in aging: endocrine consequences. Horm Res 1998;49:147-152.

69 Weinert D: Circadian temperature variation and ageing. Ageing Res Rev 2010;9:51-60.

70 Kunieda T, Minamino T, Miura K, Katsuno T, Tateno K, Miyauchi H, Kaneko S, Bradfield CA, FitzGerald GA, Komuro I: Reduced nitric oxide causes age-associated impairment of circadian rhythmicity. Circ Res 2008;102:607-614.
1 Aujard F, Cayetanot F, Bentivoglio M, Perret M: Age-related effects on the biological clock and its behavioral output in a primate. Chronobiol Int 2006;23:451-460.

72 Pittendrigh CS, Daan S: Circadian oscillations in rodents: a systematic increase of their frequency with age. Science Wash DC 1974; 186:548-550.

73 Dijk DJ, Duffy JF, Riel E, Shanahan TL, Czeisler CA: Ageing and the circadian and homeostatic regulation of human sleep during forced desynchrony of rest, melatonin and temperature rhythms. J Physiol 1999;516 (Pt 2):611-627.

74 Duffy JF, Zeitzer JM, Rimmer DW, Klerman EB, Dijk DJ, Czeisler CA: Peak of circadian melatonin rhythm occurs later within the sleep of older subjects. Am J Physiol Endocrinol Metab 2002;282:E297-E303.

75 Dijk DJ, Duffy JF: Circadian regulation of human sleep and age-related changes in its timing, consolidation and EEG characteristics. Ann Med 1999;31:130-140.

76 Yoon IY, Kripke DF, Elliott JA, Youngstedt SD, Rex KM, Hauger RL: Age-related changes of circadian rhythms and sleep-wake cycles. J Am Geriatr Soc 2003;51:1085-1091.

77 Cajochen C, Munch M, Knoblauch V, Blatter $\mathrm{K}$, Wirz-Justice A: Age-related changes in the circadian and homeostatic regulation of human sleep. Chronobiol Int 2006;23:461474.

78 Kondratov RV, Kondratova AA, Gorbacheva VY, Vykhovanets OV, Antoch MP: Early aging and age-related pathologies in mice deficient in BMAL1, the core componentof the circadian clock. Genes Dev 2006;20:18681873.

79 Fu L, Pelicano H, Liu J, Huang P, Lee C: The circadian gene Period2 plays an important role in tumor suppression and DNA damage response in vivo. Cell 2002;111:41-50.

-80 Davidson AJ, Sellix MT, Daniel J, Yamazaki S, Menaker M, Block GD: Chronic jet-lag increases mortality in aged mice. Curr Biol 2006;16:914-916.

81 Filipski E, Subramanian P, Carriere J, Guettier C, Barbason H, Levi F: Circadian disruption accelerates liver carcinogenesis in mice. Mutat Res 2009;680:95-105.

-82 Matsuo T, Yamaguchi S, Mitsui S, Emi A, Shimoda F, Okamura H: Control mechanism of the circadian clock for timing of cell division in vivo. Science 2003;302:255-259.

83 Jung-Hynes B, Reiter RJ, Ahmad N: Sirtuins, melatonin and circadian rhythms: building a bridge between aging and cancer. J Pineal Res;48:9-19.

84 Prinz PN: Age impairments in sleep, metabolic and immune functions. Exp Gerontol 2004:39:1739-1743.

85 Duffy JF, Willson HJ, Wang W, Czeisler CA: Healthy older adults better tolerate sleep deprivation than young adults. J Am Geriatr Soc 2009;57:1245-1251. 